\title{
Study of Tensile Strength Test of Oxi-Asetyline Welding with the Addition of Borax to St 37 Steel
}

\section{Studi Uji Kekuatan Tarik Hasil Las Oxi-Asetyline dengan Penambahan Boraks Pada Baja St 37}

\author{
Bagas Ariya Dipangga ${ }^{1}$, Prantasi Harmi Tjahjanti ${ }^{2}$ \\ \{ b.arya80@yahoo.co.id ${ }^{1}$, prantasiharmi@umsida.ac.id ${ }^{2}$ \} \\ Universitas Muhammadiyah Sidoarjo, Indonesia ${ }^{1}$, Universitas Muhammadiyah Sidoarjo, Indonesia ${ }^{2}$
}

\begin{abstract}
The use of welding in industry today is very broad, including shipping, machinery, construction and others. The aim of this research was to study the welding results of two types of metal with different melting points, namely low carbon steel ST37 with brass filler and borax added during the welding process using OAW (Oxygent Acetyline Welding) welding. The specimen size is $170 \mathrm{~mm}$ long, $50 \mathrm{~mm}$ wide and $8 \mathrm{~mm}$ thick. As for the test method with the addition of borax, then look at the results of the number of porosity, weld defects and differences in tensile strength in each specimen by conducting penetrant liquid testing and tensile testing with ASTM E-8 standards. The results of the penetrant liquid test showed that welding ST 37 steel using borax as an additional material produced welding with the smallest porosity and even no defects at all compared to specimens without using borax. The results of the tensile test show that the addition of borax has a tensile strength value of $2000 \mathrm{kgf} / \mathrm{mm}^{2}$. This value is greater than without the addition of borax.
\end{abstract}

Kewords - oxy-acetyliney welding, ST 37; Brass; Borax; Tensile strength test

Abstrak. Penggunaan las di industri saat ini sangat luas, meliputi perkapalan, permesinan, kontruksi dan lainnya. Tujuan penelitian adalah mengkaji hasil las dua jenis logam yang berbeda titik leburnya, yaitu baja karbon rendah ST37 dengan bahan pengisi kuningan serta ditambahkan boraks saat proses pengelasan tersebut dengan menggunakan las OAW (Oxygent Acetyline Welding). Ukuran spesimen yaitu panjang $170 \mathrm{~mm}$, lebar $50 \mathrm{~mm}$ dan tebal $8 \mathrm{~mm}$. Adapun Metode pengujiannya dengan penambahan boraks, selanjutnya di lihat hasil jumlah porositas, cacat las dan perbedaan kekuatan tarik pada setiap spesimen dengan melakukan pengujian penetrant liquid dan pengujian tarik dengan standar ASTM E-8. Hasil dari pengujian penetrant liquid menunjukkan bahwa pengelasan baja ST 37 dengan menggunakan bahan tambahan boraks menghasilkan pengelasan dengan porositas terkecil bahkan tidak ada cacat sama sekali dibandingakan dengan spesimen tanpa menggunakan boraks. Hasil pengujian tarik menunjukan penambahan boraks memiliki nilai kekuatan tarik $2000 \mathrm{kgf} / \mathrm{mm}^{2}$. Nilai itu lebih besar dibandingkan tanpa penambahan boraks.

Kata Kunci - Oxygent Acetyline Welding; baja ST 37; kuningan; boraks; uji kekuatan tarik

\section{Pendahuluan}

\subsection{Latar Belakang}

Laju perkembangan teknologi terus mengalamii peningkatan di era modern. Penggunaan las di bidang industri sangat luas sekali, meliputi pagar kanopi rumah, permesinan, karoseri, kontruksi jembatan dll. Disamping untuk berbagai macam kontruksi, las dapat memperbaiki cacat pada logam dari hasil pengecoran, dan mempertebal suatu logam yang telah aus akibat adanya gesekan saat pemakaian.(wiryosumarno dan okumura; 2004). Pengertian pengelasan adalah cara menyatukan logam dengan cara meleburkannya melalui proses pemanasan. Berdasarkan Deutche Industrie Normen (DIN) las di definisikan sebagai ikatan metalurgi pada sambungan logam yang diperoleh dari keadaan leleh atau cair. [10], [11]

Prosess pengelasan gas adalah proses pengelasan yang dapat memadukan antara baja dengan kuningan dan ditambahkan boraks pada prosesnya, Pengelasan OAW(Oxy acetylene welding) yaitu pengelasan dengan cara kerja membakar bahan bakar yang berupa gas dengan $\mathrm{O} 2$, sehingga menimbulkan nyala api yang kemudian dipakai untuk melelehkan logam induk maupun logam pengisi...[11]

\subsection{Batasan Masalah}

Batasan masalah ini dibuat agar pembahasann dalam penelitian ini tidak meluas keluar bahasan yang telah ditentukan. Adapun matasalah diantaranya yaitu:

1. Bahan tambah yang akan dipakai adalah broaks.

2. Proses pengelasan menggunakan las OAW (Oxy Acetylene Welding).

3. Bahan pengisi menggunakan kawat las kuningan. 
4. Bahan kerja atau material yang digunakan adalah Baja ST 37.

5. Kampuh yang digunakan adalah kampuh V.

6. Pengujian menggunakan Uji Tarik dan Uji Penetran.

7. Proses pendinginan pasca pengelasan menggunakan suhu dalam ruangan.

8. Standar yang digunakan pada uji tarik adalah ASTM E8/E8 M-09.

\subsection{Rumusan Masalah}

Berasarkan penjelasan latar belakang di atas akan diperoleh rumusan masalah sebagai berikut:

1. Bagaimana pengaruh penambahan boraks dalam pengelasan OAW dengan bahan pengisi kuningan pada bahan kerja baja ST 37 ?

2. Bagaimana porositas atau cacat las pada sambungan las OAW menggunakan bahan tambah boraks dengan bahan pengisi kuningan pada bahan kerja ST 37 ?

3. Bagaimana nilai kekuatan tarik sambungan las OAW menggunakan bahan tambah boraks dengan bahan pengisi kuningan pada bahan kerja ST 37

\subsection{Tujuan Penelitian}

Berdasarkan pendahuluan yang telah dipaparkan diatas, maka dapat ditentukan beberapa tujuan dari pene;itian sebagai berikut :

1. Untuk mendapatkan suatu sambungan pengelasan OAW (Oxy Acetylene Welding) dengan menggunakan dua material logam yang berbeda dam memiliki titik lebur yang berbeda.

2. Untuk mengetahui pengaruh penambahan boraks terhadap jumblah porositas dan cacat pada pengelasan OAW (Oxy Acetylene Welding) dengan menyambungkan baja ST37 dan kuningan.

3. Untuk mengetahuii perbedaan kekuatan tarik, regangan dan modulus elastisitas pada sambungan las baja ST37 dengan kuningan sebagai logam pengisi dan boraks sebagai media campuran antara logsm induik dsan pengisi.

\subsection{Manfaat Penelitian}

Adapun manfaat yang didapatkan dari penelitian ini, diantaranya sebagai berikut:

1. Bagi Industri Sebagai referensi pengembangan metode pengelasan yang digunakan untuk meningkatkan kekuatan tarik dan nilai pengujian struktur mikro sambungan las,serta efisiensi waktu pengelasan.

2. Bagi Akademisi Dapat dijadikan sebagai referensi kajian, sumber belajar, dan pengembangan evaluasi pembelajaran bagi mahasiswa di Jurusan Teknik Mesin.

3. Bagi Peneliti Selanjutnya Hasil penelitian ini dapat digunakan sebagai bahan referensi dan wawasan untuk dikembangkan dalam penelitian selanjutnya.

\section{METODOLOGI PENELITIAN}

Bahan

a. Plat Baja ST 37

b. Filler Kuningan

c. Serbuk Boraks

Alat

a. Mesin Las OAW (Oxy Acetylene Welding)

b. Mesin Frais

c. Mesin Gerinda

d. Mesin Uji Tarik dan Penetran

e. Alat Ukur Presisi

\section{Proses pengelasan}

Pengelasan ini menggunakan dua metode yang berbeda pertama pengelasan ditambahkan zat boraks dan kedua pengelasan tanpa menggunakan zat boraks berarti hanya logam kuningan dan Baja ST37. Sebelum di lakukan proses pengelasan Baja ST 37 sudah di tes komposisinya di laboratorium PT. Barata Indonesia. [2], [9]

1. Benda kerja ST 37

2. Ketebalan $8 \mathrm{~mm}$

3. Bahan pengisi/ filler kuningan diameter $1 \mathrm{~mm}$

4. Gas asetiline

5. Teknik pengelasan menambahkan boraks dan tanpa menambahkan boraks 
Procedia of Engineering and Life Science Vol. 1. No. 1 March 2021

Seminar Nasional \& Call Paper Fakultas Sains dan Teknologi (SENASAINS 1st)

Universitas Muhammadiyah Sidoarjo

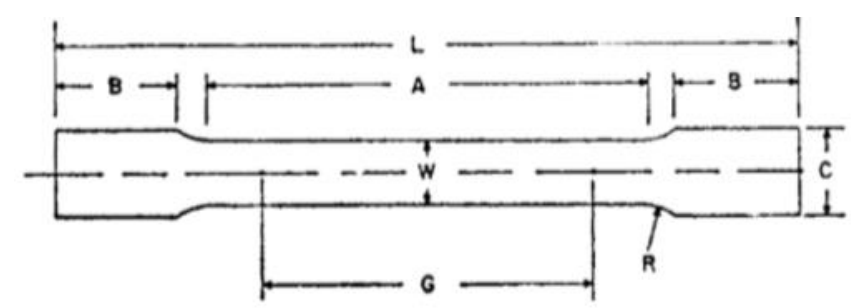

Gambar 1. sepesimen Uji Tarik Berdasarkan E8/E8M - 09

Sumber: ASTM E8/E8M - 09

\begin{tabular}{lc}
\hline & Dimensions \\
\cline { 2 - 2 } & Sheet-Type, 12.5 mm [0.500 in.] Wide \\
\cline { 2 - 2 } & mm [in.] \\
\hline G - Gage Langht & $50.060 .1[2.00060 .005]$ \\
W - Width & $12.560 .2[0.50060 .010]$ \\
T - Thickness & Thickness of material \\
R - Radius of fillet, min. & $12.5[0.500]$ \\
L - Overall lenght & $200[8]$ \\
A - Lenght of reduced section, min & $57[2.25]$ \\
B - Lenght of grip section, min & $50[2]$ \\
C - Widht of grip section, approximate & $20[0.750]$ \\
\hline
\end{tabular}

Gambar 2. Dimensi uji tarik Berdasarkan E8/E8M - 09

Sumber: ASTM E8/E8M-09

\section{Pengujian Penetran Test}

Pengujian penetran ini bertujuan untuk mengetahui kualitas hasil pengelasan yang telah di lakukan pada pagian pengelasan dari cacat yang timbul seperti porositas maupun retakan dengan cara menyemprotkan cairan penetran pada permukaan las an. [1], [2]

\section{Pengujian Tarik}

Tujuan pengujian Tarik terhadap setiap specimen yaitu untuk mengetahui kekuatan tarik dari specimen yang ditambahkan boraks maupun tidak ditambahkan boraks. Specimen uji tarik menurut standarat ASTM E8 /E8M-09. [3]

\section{Diagram Alir Penelitian}

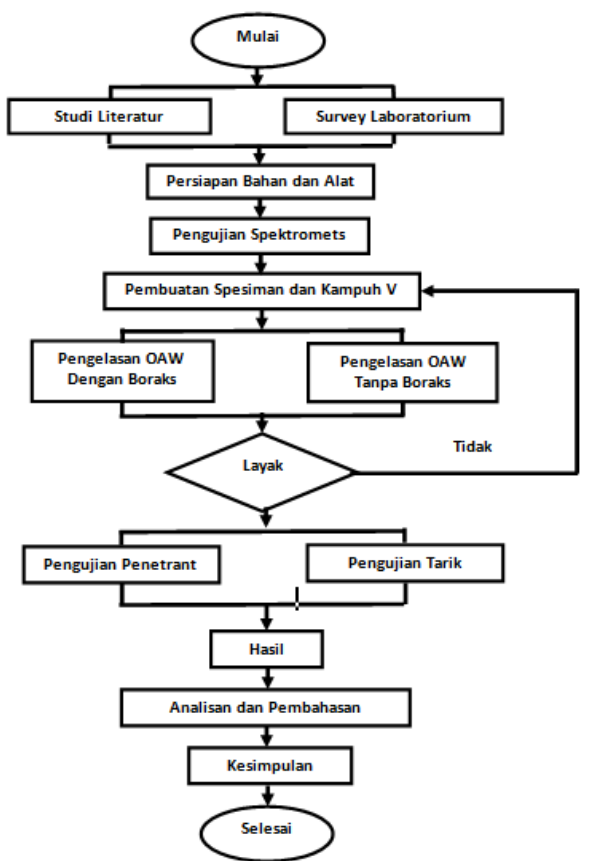

Gambar 3. Diagram Alur penelitian

\section{Hasil dan Pembahasan}

Hasil Pengujian Penetran Test 
Setelah pengujian di lakuakan didapatkan hasil dan sebuah gambaran yang dapat disimpulkan bahwa pengelasan dengan titik lebur yang berbeda yaitu ST 37 dan kuningan jika tanpa boraks membuat logam kuningan tidak menyatuh dengan sempurna dapat dilihat dari jumblah porositas dan cacat las-nya. [4]

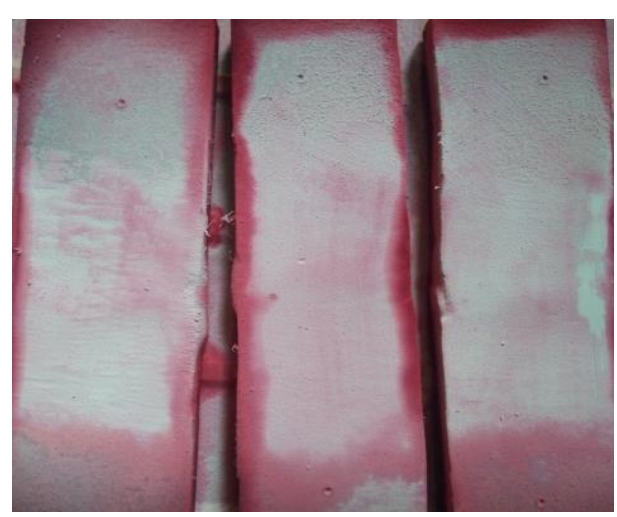

(a)

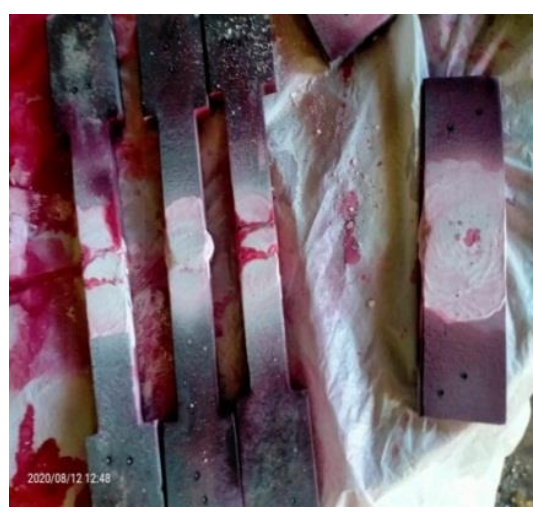

(b)

Gambar 4. Hasil Pengujian penetran a) menggunakan boraks, b) tanpa menggunakan boraks

\section{$\begin{array}{llll}\text { No Metode pengelasan } & \text { Pengujian } & \text { Porositas }\end{array}$}

\begin{tabular}{|c|c|c|c|c|}
\hline 1 & Menggunakan Boraks & Spesimen 1 & Tidak ada cacat & Tidak ada cacat \\
\hline 2 & & Spesimen 2 & Tidak ada cacat & Tidak ada cacat \\
\hline 3 & & Spesimen 3 & Tidak ada cacat & Tidak ada cacat \\
\hline 4 & & Spesimen 1 & 2 Porositas & 2 Retakan \\
\hline 5 & Boraks & Spesimen 2 & 5 Porositas & 2 Retakan \\
\hline 6 & & Spesimen 3 & 3 Porositas & 1 Retakan \\
\hline
\end{tabular}

Hasil dari pengujian diatas menunjukkan bahwa pengelasan baja ST 37 dengan menggunakan bahan tambahan boraks memberikan tingkat pengelasan dengan porositas terkecil bahkan tidak ada cacat sama sekali, sedangkan tanpa menggunakan borax cacat porositas dan retakan di pinggir area pengelasan lebih banyak sehingga dapat mempengaruhi kekuatan dari specimen saat dilakukan pengujian lebih lanjut. [5]

\section{Hasil Pengujian Tarik}

Pengujian tarik dilakukan mengetahui sifat mekanis setelah proses pengelasan. Hasil dari pengujian tarik pada umumnya berupa kekuatan tarik, kekuatan luluh, dan juga regangan. [6] 


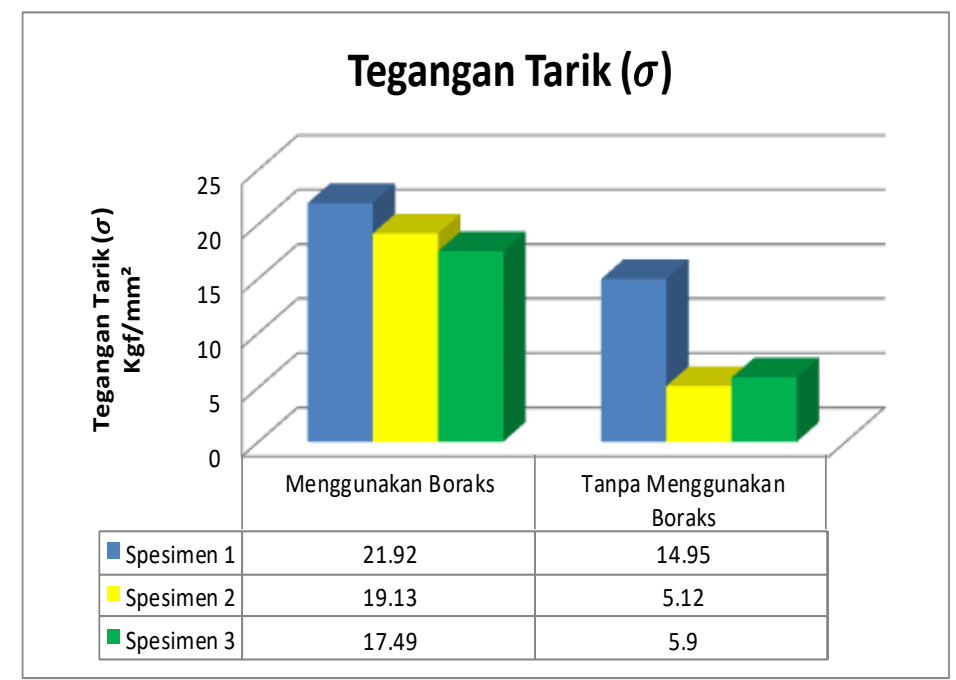

Gambar 5. Grafik tegangan tarik

Hasil dari pengujian untuk kekuatan tarik ditunjukkan pada gambar diatas, menujukan bahwa tegangan tarik pada specimen yang menggunakan boraks mempunyai nilai terbesar yaitu $21,92 \mathrm{kgf} / \mathrm{mm}^{2}$ sedangakan pada metode tanpa menggunakan boraks mempunyai nilai terbesar yaitu $14,95 \mathrm{kgf} / \mathrm{mm}^{2}$. selisih nilai tegangan tarik kedua metode ini yaitu $6,97 \mathrm{kgf} / \mathrm{mm}^{2}$. [7]

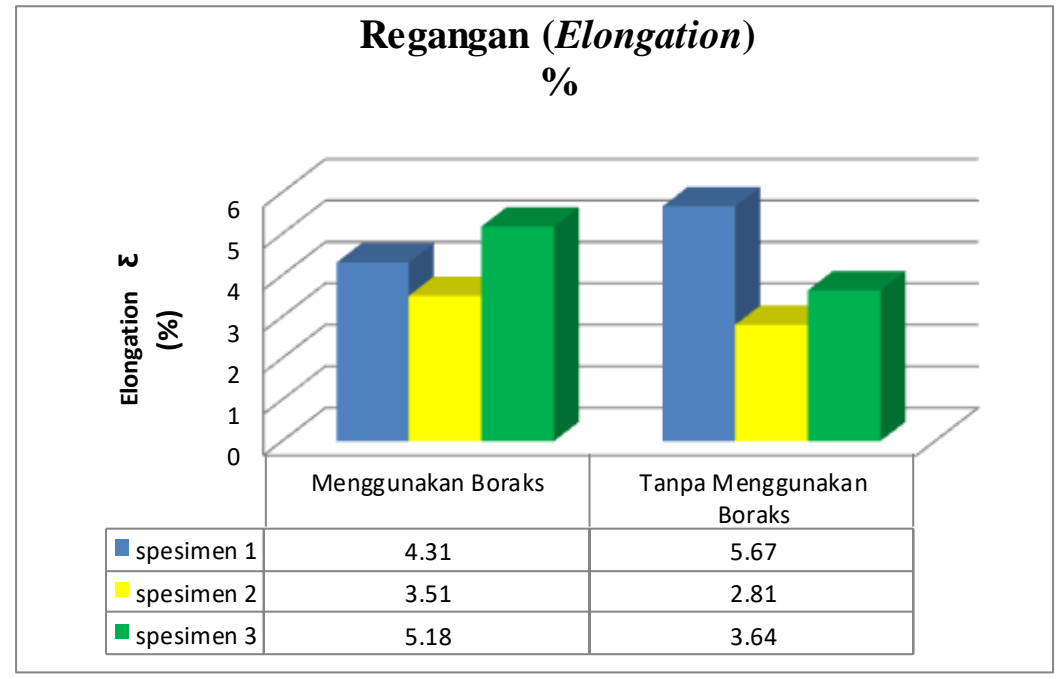

Gambar 6. Grafik regangan tarik

Hasil pengujian untuk regangan tarik dari ke enam specimen ditunjukkan pada diagram dia atas . regangan tarik pada specimen tanpa menggunakan boraks tertinggi yaitu 5,67\% sedangkan regangan tarik specimen yang tanpa menggunakan boraks tertinggi yaitu 5,18\% , berbanding dengan kekuatan tarik ,metode tanpa menggunakan boraks lebih tinggi nilainya disbanding dengan boraks yang memiliki selisisih $0,47 \%$. [8] 


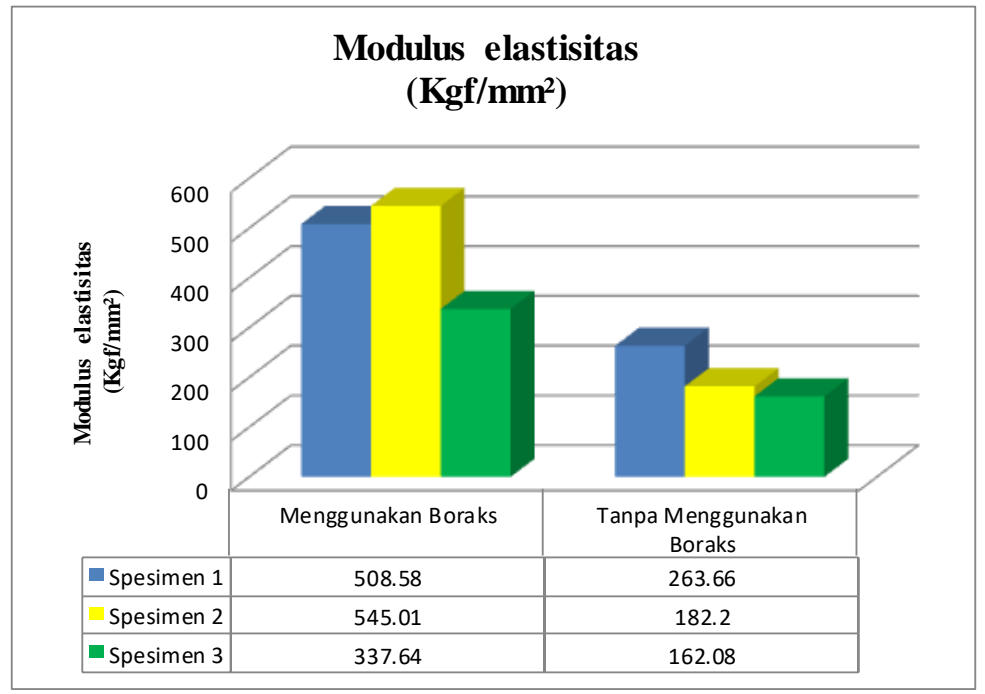

Gambar 7. Grafik modulus elastisitas

Hasil pengujian untuk modulus elastisitas dari ke enam specimen ditunjukkan dari diagram di atas dengan modulus elastisitas tertinggi $545,01 \mathrm{kgf} / \mathrm{mm}^{2}$, nilai ini didapat dari specimen dua dengan metode penambahan boraks saat pengelasan. Sedangkan untuk metode tanpa penambahan boraks memiliki nilai tertinggi 263,66 $\mathrm{kgf} / \mathrm{mm}^{2}$, selisih kedua metode tersebut adalah $281,35 \mathrm{kgf} / \mathrm{mm}^{2}$. [9]

\section{KESIMPULAN}

\section{KESIMPULAN}

1. Boraks sangat berpengaruh dalam penyambungan dua logam yang titik leburnya berbeda dengan las OAW (Oxy Acetylene Welding), dapat dilihat secara visual dari bentuk pengelasan, tingkat kesulitan dan cacat las yang tidak ada sama sekali pada specimen yang ditambahkan boraks saat pengelasan.

2. Penyambungan ST 37 dengan kuningan jika ditambahkan boraks akan mendapatkan hasil yang baik karena hasil las dari metode ini tidak memiliki cacat las dan porositas. Hasil ini ditunjukan setelah seluruh specimen di uji penetran metode penambahan boraks tidak memiliki cacat las dan porositas sedangkan metode tanpa penambahan boraks yaitu:
a. Specimen satu $=2$ porositas dan 2 retakan
b. Specimen dua $=5$ porositas dan 2 retakan
c. Specimen tiga $=3$ porositas dan 1 retakan

3. Nilai kekuatan tarik terbesar yaitu $21,92 \mathrm{kgf} / \mathrm{mm}^{2}$ diperoleh dari specimen satu dengan metode penambahan boraks, ini dikarenakan karena kecilnya nilai porositas dari spesimen. Sedangakan metode tanpa penambahan boraks memiliki nilai rata-rata yaitu $8,66 \mathrm{kgf} / \mathrm{mm}^{2}$, dikarenakan banyaknya jumblah cacat las dan porositas pada setiap specimen uji. Pada pengujian tarik juga di dapatkan nilai regangan rata-rata yaitu: 4,33\% untuk metode penambahan boraks dan 3,86\% untuk metode tanpa penambahan boraks.

\section{SARAN}

1 Untuk penggunaan gas asetiline saat proses pengelasan OAW (Oxy Acetylene Welding) disarankan menggunakan gas asetilne yang lebih murni dari gas asetiline yang digunakan pada umumnya.

2 Perlu dilakukan penelitian dengan metode pengujian yang lebih akurat atau valid seperti uji struktur mikro atau uji radiograpi pada hasil lasan.

3 Perlu dilakukan penelitian dengan material logam yang lain agar diketahui kekuatan kombinasi dari setiap material logam tersebut

\section{REFERENSI}

[1] Creswell, John W. 2016. Research Design: Pendekatan Metode Kualitatif, Kuantitatif, dan Campuran. Yogyakarta: Pustaka Pelajar.R. Hayes, G. Pisano, D. Upton, and S. Wheelwright, Operations, Strategy, and Technology: Pursuing the competitive edge. Hoboken, NJ: Wiley, 2005. 
[2] Hardiansyah, T. 2018. Pengaruh Variasi Kuat Arus dan Wire Feed Rate Pada Baja Karbon Rendah Terhadap Kekuatan Tarik Hasil Pengelasan GMAW. Skripsi Tidak Diterbitkan. Malang: Fakultas Teknik Universitas Negeri Malang.A. Rezi and M. Allam, "Techniques in array processing by means of transformations, " in Control and Dynamic Systems, Vol. 69, Multidemsional Systems, C. T. Leondes, Ed. San Diego: Academic Press, 1995, pp. 133-180.

[3] Hartati, F, K. 2017. Analisis Boraks Secara Cepat, Mudah dan Murah pada Kerupuk. Surabaya: Universitas Dr. Soetomo H. Ayasso and A. Mohammad-Djafari, "Joint NDT Image Restoration and Segmentation Using Gauss-Markov-Potts Prior Models and Variational Bayesian Computation," IEEE Transactions on Image Processing, vol. 19, no. 9, pp. 2265-77, 2010. [Online]. Available: IEEE Xplore, http://www.ieee.org. [Accessed Sept. 10, 2010].

[4] Mukhadis, A. 2016. Metodologi Penelitian Kuantitatif: Bidang Pendidikan dan Contoh Aplikasinya. Malang: Aditya Media Publishing..

[5] Sugiyono. 2015. Metode Penelitian Kuantitatif, Kualitatif, dan R\&D. Bandung: Alfabeta.

[6] J. R. Beveridge and E. M. Riseman, "How easy is matching 2D line models using local search?" IEEE Transactions on Pattern Analysis and Machine Intelligence, vol. 19, pp. 564-579, June 1997.

[7] E. H. Miller, "A note on reflector arrays," IEEE Transactions on Antennas and Propagation, to be published.

[8] ASTM International (E8-8M-09). 2010. Standart Test Methods for Tension Testing of Metalic Materials. United States of America

[9] Andinata, F., dkk. 2012. Pengaruh pH Larutan Elektrolit Terhadap Tebal Lapisan Elektroplating Nikel Pada Baja St 37. Surabaya: Universitas Negeri Surabaya

[10] Salahuddin Junus, Jurnal ROTOR, Volume 4 Nomor1, Januari 2011.

[11] Trinova Budi Santoso, Solichin, Prihanto Tri Hutomo, Pengaruh Kuat Arus Listrik. JURNAL TEKNIK MESIN, TAHUN 23, NO. 1, APRIL 2015 